\title{
Important Business Considerations For Successful Entry Into The China Market
}

\author{
Sooun Lee, Miami University, USA \\ Joshua Schwarz, Miami University, USA \\ James Coyle, Miami University, USA \\ Thomas Boulton, Miami University, USA \\ Naoki Kameda, Doshisha University, Japan
}

\begin{abstract}
This case requires students to practice international management skills as they consider a wide range of important business questions for a medium-size US company looking to enter the Chinese market. Over the course of four separable modules, students determine the best entry strategy for the company, how to finance the project, how to select the best project manager and how to develop an initial marketing plan. Faculty can choose to assign some or all modules. In addition, the authors, who have implemented this case multiple times with American, Chinese, South Korean and Japanese students working together, discuss the cross-cultural lessons they have learned and recommend ways to improve cross-cultural communication. Specific case questions and case resources are provided.
\end{abstract}

Keywords: China; Entry Strategies; Finance; Human Resource Selection; International Management; Marketing

\section{INTRODUCTION}

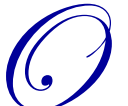

hio Manufacturing International (OMI) is a medium-size U.S. company headquartered in Cincinnati, Ohio, USA. It has been in business for about 25 years and is mainly involved in manufacturing and marketing a range of consumer products. The company's annual net sales are about US\$ 200 million, as referred to in the financial statements in Exhibit 1 (see Appendix). OMI operates at several locations around the world through many wholly-owned subsidiaries, joint ventures, export offices, and a few licensing agreements. OMI sells its products all over the world, but primarily in North America and Europe. The closely-held ownership of OMI is comprised of major investors from around the world: $36 \%$ of the firm is owned by Japanese investors, $25 \%$ by American investors, $10 \%$ by Korean investors, $14 \%$ by Europeans, and $15 \%$ from a sovereign wealth fund from Dubai.

\section{CASE QUESTIONS}

\section{Selecting a Successful Entry Strategy}

A. Evaluate the advantages and disadvantages of various entry strategies (Joint Venture, Wholly Owned Enterprise, Representative Office for importing from Japan) that the company could use to produce and sell specialty bicycles in China.

B. What entry strategy do you recommend and why?

C. Would you recommend OMI's expansion plan under the current economic conditions? Why or Why not?

\section{Financial Projections}

A. What cost of capital (discount rate) should OMI use to evaluate the project? Why?

B. Given the answer to part A, what are the NPV and IRR of the project?

C. Assuming that OMI decides to raise external capital in conjunction with the expansion, do you recommend equity or debt? Why? Discuss the pros and cons of both options. 
D. Should OMI raise its external capital in the United States, Japan, or China? What are some reasons why OMI might choose to raise external capital outside of the United States?

\section{Selecting a Project Manager}

A. No matter how the above questions are decided, what important criteria are recommended for the organization to consider for evaluating candidates (Robert, John, and Lisa) and which information should be ignored? Are there any potential problems with the selection process as described and what suggestions could be made on ways to improve it?

B. Who would be best to lead the expansion project? Why?

\section{Marketing}

A. What target markets in China do you recommend OMI pursue and why?

B. What are the key determinants of consumer behavior regarding the purchase of this product?

C. What promotional mix for these market(s) do you recommend and why?

\section{CASE RESOURCES}

The following list of resources provides students with background understanding of the bicycle market in China and the US, relevant legal issues, and Chinese consumer behavior.

- $\quad$ History of Bicycles in China: http://www.imperialtours.net/bicycle.htm

- Worldwide Bicycle Statistics: http://www.ibike.org/library/statistics-data.htm

- $\quad$ US Bicycle Industry: http://nbda.com/page.cfm?PageID=34

- China Bike International Fair: http://www.chinacycle.com.cn/

- $\quad$ Electric Bike: http://www.fastcoexist.com/1681004/electric-bikes-have-invaded-china-is-the-us-next

- $\quad$ Navigate the Chinese Social Media Landscape: http://blog.mynewsdesk.com/2012/01/05/brief-intro-tonavigating-the-chinese-social-media-landscape/

- The Chinese Dream, Thoughtful China: http://www.thoughtfulchina.com/en/the-chinese-dream-stabilitysecurity-and-wealth-trump-personal-freedom-en.html

- $\quad$ Emotional Branding, Thoughtful China: http://www.thoughtfulchina.com/emotional-branding-en.html

- China's Media Landscape, Thoughtful China: http://www.thoughtfulchina.com/en/chinas-media-landscapein-2012-en.html

- $\quad$ Building Brands with Baidu, Thoughtful China: http://www.thoughtfulchina.com/en/building-brands-withbaidu-en.html

- $\quad$ Application of US Laws Abroad: http://www.eeoc.gov/policy/docs/extraterritorial-vii-ada.html

\section{SELECTING A SUCCESSFUL ENTRY STRATEGY MODULE}

While OMI has some limited manufacturing operations in Asia, the company would like to expand in Asia. CEO Hans Schmitz (born in the USA of German parents) is particularly interested in China. Although he doesn't have great contacts or experiences in China, he has old friends and ties in Japan and has established some networking in South Korea and Singapore. Given his background as an engineer, CEO Schmitz is very interested in selling high-quality bicycles in China. Along with the corporate board of directors, Schmitz is in the review phase of deciding about an entry strategy for selling specialty lightweight mountain bicycles in China. According to informal research by OMI, similar bicycles sell for about $\$ 500-\$ 1,000$ in the U.S. stores. His internal management staff has suggested three alternatives for the Board to consider: (1) joint venture with an existing bicycle manufacture located in or near Beijing, China, (2) wholly-owned enterprise in China, and (3) representative office in China to import bicycles produced from a company-owned plant near Kyoto, Japan.

The corporate board of directors at OMI desires a sales volume in China of about US\$20 million annually. There are at least three potential joint venture partners in China; the leading candidate has about 900 employees, has 
been making regular bicycles for many years, and recently started a limited production line of high-end mountain bikes. Exploring the wholly-owned subsidiary route, OMI recently discussed leasing a parcel of land (about 25,000 square meters) near Beijing for 70 years from the Chinese government; pricing information is not yet available, but OMI understands that the land lease cost will be very inexpensive. If the company chooses the representative office option, an existing plant near Kyoto that manufactures aluminum siding and bicycle parts for sale within Japan is expected to provide production capacity. Although this plant is not currently doing well, it has excess capacity and excess land. Existing equipment can be easily modified for the bicycle production. According to CEO Schmitz, labor costs in Japan have been slowly decreasing relative to labor cost in China for the last decade; still the labor costs are very high compared to that of China. Schmitz also pointed out that, in Japan, OMI can maintain top quality products with 'Made in Japan' country premium and continue to make extensive use of a part-time work force including college students, housewives, and others seeking second jobs.

Among many factors to consider, CEO Schmitz views the following factors (listed in alphabetical order) as important to choosing the best entry strategy for OMI:

$\begin{array}{ll}\text { - } & \text { Current Market/Competition } \\ \text { - } & \text { Excess Capacity in Japan } \\ \text { - } & \text { Innancial Requirements } \\ \text { - } & \text { Intellectual Property Rights } \\ \text { - } & \text { Management Control } \\ \text { - } & \text { Sales Potential } \\ & \text { Speed to Market Entry }\end{array}$

\section{Teaching Notes: Selecting a Successful Entry Strategy}

In order to determine an optimal entry strategy to China for the Ohio Manufacturing International (OMI), students first need to understand/clarify the goal/objectives and constraints (e.g., time and resource) of the project. Due to the limited information about the project given in the scenario, students are encouraged to make necessary assumptions and include them as a part of the project definition in their final paper.

After the project is clearly defined, students can be guided to identify and evaluate relevant international business topics in China to achieve the goal/objectives defined. The study topics may include, but are not limited to, the local consumers and market, demand for high-end bicycles, manufacturing and investment environment, legal and regulatory issues for a foreign investor, protection of intellectual property rights, local business practices and culture, etc.

What makes the case more interesting and complex is the potential use of the idle manufacturing capacity in Japan. Sourcing from multiple countries is not an unusual business strategy utilized by multinational firms nowadays. To add the idle capacity in Japan into the study matrix, students need to analyze the manufacturing and labor costs, export/import-related issues, such as shipping costs and tax issues, and even the effect of a country name brand image between the two Asian countries - China and Japan.

In addition, students need to evaluate the pros and cons of the three entry strategies suggested - joint venture (JV), wholly owned enterprise (WOE), and representative office (RO). With RO approach, OMI can import assembled bicycles from the Japanese plant instead of manufacturing it in China. At this stage, students can evaluate each strategy based on the defined project goal/objectives and constraints to select a best entry strategy for a recommendation. Answers may vary depending on how students define/prioritize the project goal/objectives and constraints and pros and cons of each entry option.

In general, a company may have more control over management and protecting their intellectual property rights with WOE or RO options, but these two strategies may cost more and may be less effective in starting a business, especially in a foreign country. With a JV approach, a company may access local business experience and 
networks with ease with the help of a local partner company. This approach also may require less financial investment and time to start a business. However, it may lead to conflicts/disputes between the partners in management and a theft of intellectual property right, etc.

This scenario can be run effectively as an open-ended assignment to students. The quality of their justification as to why students chose an approach over others and their supporting recommendations will be used as a main grading criterion.

\section{FINANCIAL PROJECTIONS MODULE}

OMI's financial managers have constructed basic financial projections for the expansion project. Those projections can be seen in Exhibit 2 (see Appendix).

The required initial investment depends on the entry mode chosen. A joint venture or wholly-owned subsidiary is expected to require a $\$ 25$ million initial investment, while the representative office option is expected to require a \$20 million initial investment. Regardless of which entry method is selected, the initial investment is expected to have zero salvage value at the end of the project. The project also requires an additional $\$ 5$ million investment in working capital. No subsequent investments in working capital are expected. Beyond year 3 , the company expects operating cash flow from the project to grow at three percent per year in perpetuity.

The company typically treats bicycle expansion projects in the US and Europe as 10-year projects and uses a 12 percent cost of capital. However, OMI management believes that an Asian expansion is riskier than its prior investments in this area. There are currently three publicly traded bicycle manufacturers in China. OMI estimates that the average cost of capital for these companies is 15 percent.

\section{Financing the Project}

OMI has been successful and has accumulated cash and near-cash which it can use to grow the business. At the end of last year, the company had nearly $\$ 13$ million in cash on its balance sheet. However, the executive team is worried that the size of the expansion will drain a significant portion of the company's available cash and has discussed the possibility of raising external capital to finance the project. As previously discussed, OMI is a closely held corporation with major investors around the world. One possibility being considered is to raise equity capital by taking the company public and listing the company's stock on a major international stock exchange. OMI and its advisors have considered several international markets for a potential initial public offering (IPO), including the United States, Japan, and China. In addition, early investors in the company have raised the possibility of selling some of their stake in an eventual IPO.

A second option that OMI has discussed with its advisors is to borrow the capital needed for the project in the public debt markets. Due to the company's performance and profitability, OMI has an excellent credit rating and expects to be able to borrow on very favorable terms. The company is no stranger to debt, having borrowed money from banks to finance past investments. Recently, the company has been aggressively paying down its outstanding debt, resulting in a net reduction of approximately $\$ 15$ million over the past two years. If OMI chooses this option, the company's advisors have recommended dollar-denominated bonds sold in the United States (US\$). However, management is intrigued by the possibility of issuing Samurai or Panda bonds in Japan or China, respectively. Given the company's international investor base and operations, any OMI equity or debt issue is expected to be wellreceived by the investment community.

\section{Teaching Notes: Financing the Project}

A. What cost of capital (discount rate) should OMI use to evaluate the project?

Why? This question allows the instructor to reinforce several core capital budgeting concepts in a straightforward setting. Specifically, instructors are encouraged to focus on (i) the relation between risk and expected return and (ii) the justification for using project-specific discount rates. A discussion on the relation 
between risk and expected return might center on why the risk of the Asian expansion differs from that of prior US and European bicycle expansion projects. Students are likely to cite competition and culture as two factors that contribute to the difference in risk.

Following a discussion on the relation between risk and expected return, this question could also be used to introduce the pitfalls of using a single discount rate to evaluate all of a firm's projects. Instructors might motivate the discussion using the illustration in Exhibit 3 (see Appendix).

By focusing on areas A \& B in Exhibit 3, instructors can easily convey the pitfalls of using a single discount rate for all projects. Specifically, when a company uses a single discount rate for all projects, they will reject projects that fall in area A (below the single rate but above the project-specific rate). However, projects in Area A should be accepted because they provide a return that is adequate for their level of risk. Area B poses a slightly different problem (below the project-specific rate, but above the single rate). Projects in this area are accepted by companies that use a single discount rate but should be rejected because they do not provide an adequate return given their level of risk.

B. Given the answer to Part A, what are the NPV and IRR of the project?

Calculating the NPV and IRR requires students to first calculate the relevant cash flows for the Asian expansion project. The case document and Exhibit 2 (see Appendix) provide the information required to determine the project cash flows. The NPV and IRR of the project depend, in part, on the entry mode chosen. The tables in Exhibit 4 (see Appendix) detail the NPV and IRR for each option (note that the implications are the same for a joint venture and wholly-owned subsidiary).

Calculations are illustrated here using the joint venture/wholly-owned subsidiary case. These options require an initial investment of $\$ 25$ million and an additional investment in net working capital of $\$ 5$ million. Exhibit 2 reports pro forma income statement numbers for the project for years 1 through 3. Operating cash flow is calculated for each year using the following formula: $\mathrm{OCF}=\mathrm{EBIT} \times\left(1-\mathrm{T}_{\mathrm{c}}\right)+$ Depreciation. For example, $\mathrm{OCF}_{3}$ is calculated as follows: $\mathrm{OCF}_{3}=7,000 \times(1-0.25)+2,000=7,250$. Finally, the terminal value is calculated using the formula for a growing perpetuity, as the case states that operating cash flow is expected to grow at three percent per year beyond year 3. This calculation is $\mathrm{PV}_{3}=\left[\mathrm{CF}_{3} \times(1+\mathrm{g})\right] /(\mathrm{r}-\mathrm{g})=[7,250 \times(1.03)] /(0.15-0.03)=62,229$. These calculations assume that students agree that a 15 percent discount rate is appropriate. It is simple to calculate the NPV and IRR for different discount rate assumptions.

Regardless of the entry method chosen, the NPV is positive and the IRR is greater than the project-specific cost of capital. This suggests that, given the current assumptions, the project will add value for existing shareholders and should be pursued by OMI.

C. Assuming that OMI decides to raise external capital in conjunction with the expansion, do you recommend equity or debt? Why? Discuss the pros and cons of both options.

The purpose of this question is to introduce the advantages and disadvantages of debt and equity. The table in Exhibit 5 (see Appendix) summarizes some of the key advantages and disadvantages of both.

D. Should OMI raise its external capital in the United States, Japan, or China? What are some reasons why OMI might choose to raise external capital outside of the United States?

The decision of where to raise capital should be tied to the entry mode chosen, which impacts the currency exposure of OMI. For example, if the Japanese manufacturing facility is used for the expansion, the project exposes OMI to both Japanese Yen and Chinese Yuan. This exposure is, in large part, the result of customer and supplier relationships. If the entry mode does not include the use of the Japanese manufacturing facility, exposure may be limited to the Chinese Yuan.

Regardless of the entry mode, there are several things for the firm to consider when deciding where to raise capital. Given that OMI is a US-based company, they might find it easier and cheaper to raise capital at home where 
they already have relationships with financial institutions and potential investors. In addition, the US capital markets are the most liquid in the world.

However, there are several reasons OMI might consider raising capital abroad. Common reasons cited for raising capital abroad include hedging, regulatory requirements, and access to new investors. A discussion of hedging might center on the sale of bicycles in China. Clearly, Chinese consumers will pay OMI with Chinese Yuan. However, as a US-based company, OMI prefers Dollars. Whenever the company converts Yuan to Dollars, it is exposed to the prevailing exchange rate, which could negatively (or positively) impact profitability. However, if the company borrows in Chinese Yuan, the company can use the cash flows from the sale of bicycles in China to make interest payments on its debt. This eliminates the need to convert Yuan to Dollars, thereby reducing the firm's exposure to exchange rate risk. Also, it might be the case that regulations require that firms raise some portion of their capital locally. Even if this is not the case, raising capital locally could demonstrate a deeper commitment to the investment in Japan and/or China, and provide some goodwill for OMI in the eyes of local regulators. Finally, OMI might raise capital abroad to gain access to new investors. This might be the case if OMI's US-based investors are not interested in investing more in the company or if OMI is seeking to broaden its investor base.

\section{SELECTING A PROJECT MANAGER MODULE (HUMAN RESOURCES MANAGEMENT)}

No matter which entry mode strategy is selected, OMI desires to have quite a bit of control over the manufacturing and marketing of bicycles in China. OMI is setting up a team to further research and explore opportunities. It is expected that this team will eventually serve as the management core for bicycles in China. At this time, the company is reviewing candidates for the position of project manager and CEO Schmitz hopes that the person selected will eventually serve as the General Manager when the bicycle manufacturing and marketing become fully implemented. CEO Schmitz is so optimistic that he hopes this can occur in as little as 18 months.

OMI has posted the managerial position of Project Manager and narrowed a lengthy list of applicants down to three people. Position descriptions can be found in Exhibit 6 (see Appendix). All of the three are outsiders (not employed by OMI) and all are citizens and residents of the United States. To narrow the list further, OMI has established the following selection process:

A selection committee was formed consisting of the CEO, Vice President of Marketing (who also heads-up the legal department), Vice President of Operations and Vice President of Human Resources. Each candidate had a separate two-hour interview with each committee member then the candidate and selection committee all had dinner together. To aid in the selection process, each candidate took a battery of tests consisting of an intelligence test, physical fitness test and handwriting analysis (graphology). After the interview, each person on the selection committee rated each candidate on a scale of 1-10 based on their impressions of the candidate's fit for the job. Each selection committee member agreed to devise their own questions and tailor them to meet the specific background of each of the separate candidates. They further agreed that higher scores indicated stronger candidates. The summary of scores is displayed in Exhibit 7 (see Appendix). A brief biographical sketch for each of the three candidates (listed alphabetically) follows:

Robert J. Clinton -- Bob Clinton, age 35, has a bachelor's degree (graduated cum laude) in industrial engineering from UCLA and a recent MBA degree from Stanford University with an emphasis in international trade. Bob has three years of industrial experience working as a production manager at a bicycle manufacturer in California before returning for his MBA. After his MBA, he worked in the Silicon Valley area in computer sales and service. Bob (originally from San Diego, California) has excellent communications skills, very good organizational experiences, and is fluent in Spanish. He self-identifies as very flexible, culturally sensitive, and a hard-nosed manager who can get the task done effectively and efficiently. In the interview process, Bob came across as taskoriented, quick witted, well-educated, a top-down manager and a risk taker. He regularly attends the Catholic Church in his hometown. Other than attending a computer conference in Paris, Bob has never been outside of North America.

John Yoshio Sato -- John Sato, age 53, was born in California but grew up in Florida. All four of his grandparents emigrated from Japan to California. After graduating from the University of Florida with a degree in 
international studies and a minor in Japanese, John spent two years teaching English in Japan. He then worked for Toyota in three different locations in the United States. John then returned to school full time and completed a combination of law and MBA (finance) degrees at Florida State University, then spent four years working for Procter and Gamble $(\mathrm{P} \& \mathrm{G})$ in China, and frequently visited Asia in setting up distribution networks for P\&G. For the past 10 years, John was the President of his father's export/import business (annual sales about US\$15 million per year), but after the death of his father, that business failed due to intense competition and was finally dissolved after a family disagreement. In the interview process, John came across as skilled in management and supervision, having a strong business savvy, and an excellent understanding about Asian culture. While his demeanor is somewhat laid back and cautious, his understanding of finance; the legal system, including contract law; and employee motivation were all judged as strengths. He did not indicate any particular religious affiliation.

Lisa Wong -- Lisa Wong, age 41, was born in Ohio. Her father (a Chinese immigrant) was an entrepreneur who operated five small Chinese restaurants in Cleveland, Ohio, and her mother is an American. As a ChineseAmerican, Lisa graduated from Miami University with a major in marketing and minor in East Asian Studies. After graduation, she spent eight months in Shanghai learning the restaurant business from her uncle and cousins. Next, she spent two months each in Seoul and Tokyo learning the restaurant business from other relatives. She returned to Ohio and ran the family restaurant business for about 10 years, eventually losing control to her younger brother. During the middle part of those 10 years, she attended evening law school and received her law degree but never practiced as an attorney. Then, after some medical problems that kept her from working full-time for two years, she was given a totally clean health report by her physicians. Still single and completely out of her brother's restaurant business, she went to work as the human resource manager for a large food wholesaler in Cleveland, Ohio. In the OMI interview process, Lisa came across as an excellent communicator, very good with people skills, and knowledgeable about Asian culture (not only Chinese, but Asia in general). Evidence indicates that she is an extremely hard worker, team-oriented, a motivator of employees, intelligent, and gets along with any person or situation. She seems to have a calming character and is very flexible. She continues to follow her Buddhist upbringing.

\section{Teaching Notes: Selecting a Project Manager (Human Resource Management)}

Choosing the leader for this project is vital to its success. In any selection decision, it is critical that all procedures are designed to gather as much job-related and legal information as possible while avoiding data that may be subject to various biases inherent in many aspects of human decision-making.

The best selection decisions are based on information that is valid, reliable and legal. Valid information is predictive of future job performance. Reliable information is consistent, free from random variation. Legal information is consistent with a society's values and usually designed to protect individuals who are part of a group that has historically experienced employment discrimination.

There is a variety of selection tests commonly used around the world and they vary greatly in their ability to accurately predict future job performance. By far, the most common is the interview, which is also used in this case. Interviews are subject to a wide variety of biases, many of which are unconscious (Noe et al., 2010, p. 246) as they tend to be subjectively scored. One such bias, called "similar to me" is a tendency for interviewers to score more positively candidates having background like the interviewer's own. The interview scores, in this case, reflect this bias. Ways to reduce this and other types of interview bias are to agree on the most important job-related criteria, structure the interview so all candidates are asked the same set of questions, have multiple interviewers witness the same candidate responses through panel interviewing, and agree on scoring of candidates' responses.

Intelligence tests, on the other hand, tend to have a high level of predictive validity across a broad range of jobs. Intelligence tests are also pretty reliable as IQ test scores are usually stable over time.

Physical fitness tests are unlikely to be job-related in the case of a project manager so should not have a place in the selection process. The same is true of graphology or handwriting analysis. Although this technique is rarely used in the US, it is common in some other countries. Given that there is no evidence for the validity of this measure, it should not be used. 
In addition to concerns about validity and reliability, all selection criteria used should be legal. Title VII Civil Rights Act and other similar federal laws in the US prohibit consideration of protected class status in any employment-related decision, like selection, compensation, assignment of duties, discipline or discharge. Protected classes include race, sex, religion, color, national origin, age and disability status, among others. These laws apply to US citizens working for US companies doing business in another country (EEOC). The current selection process could run afoul of this law if disability status of the candidates is being picked up by the physical fitness test, unless fitness can be shown to be job-related. Also, there are frequent mentions of age and religion in the candidate descriptions, which is also prohibited.

Another more subtle point that students may want to discuss is the candidates' personality traits and how those might be perceived, given the cultural context within which they may be operating.

\section{MARKETING MODULE}

\section{Developing a Successful Marketing Plan}

Regardless of which entry mode strategy is chosen, OMI must have in place a clear, documented, and actionable plan to guide their decision-making in identifying profitable target markets, developing a successful marketing communications plan, and allocating an appropriate media budget. This plan must be consistent with the company's overall business objectives and goals. It also must reflect thoughtful consideration of China's economic, political, cultural and technical environment.

To get started, CEO Schmitz realizes more information has to be gathered and analyzed about the tieredcity system in China. This will allow the company to do two things: 1) identify cities representing lucrative markets for selling bicycles and 2) craft persuasive communications that reflect a good understanding of consumer behavior demonstrated in cities of different tiers. The CEO believes that consumer behavior can vary markedly across these different tiers.

Because the company has very little experience in China, the CEO knows it will take time to thoroughly understand China's rapidly changing media landscape, both traditional and non-traditional. In particular, he wants to explore the most effective marketing strategies and tactics for customer acquisition and for building awareness of this new brand.

The CEO has identified the following consumer analysis factors as being important:

- $\quad$ nature of the buying decision

- demographics and psychographics of potential markets

- $\quad$ buyer motivation and expectations

- $\quad$ perception of international vs. domestic brands

- $\quad$ media usage

Only after conducting this analysis can specific branding strategies be developed. Once completed, CEO Schmitz has identified the following promotional factors as being important in preparing a marketing communications plan:

- $\quad$ promotional goals

- promotional mix

- $\quad$ public relations opportunities

- word-of-mouth/viral marketing opportunities

As one would expect with a manufacturer, OMI's business-to-business marketing efforts to date have focused on trade show support, public relations, trade magazine print advertising, search engine optimization, and printed and electronic sales collateral. With this new venture offering the opportunity to sell directly to consumers, 
CEO Schmitz is particularly intrigued by the potential of digital branding and social media marketing due to what he perceives to be their lower costs compared to traditional media advertising. His friends in Japan, South Korea and Singapore have informed him that there are some similarities between the US and China in terms of digital branding players and services. For example, China has a dominant search engine site, Baidu, which is often referred to as "China's Google." They tell him that China has counterparts for Twitter, Facebook and Amazon as well. However, they warn him not to assume that the Chinese use social media in exactly the same way as Americans and that Chinese and US social media differ in significant ways.

\section{Teaching Notes: Developing Marketing and Branding Plans}

The Chinese media landscape has exploded, evolving from one that heavily relies on television advertising to one as rich and varied as in the West. As stated in the case, China now has social networks equivalent to the big online stars of the West (e.g., Amazon, Google, Facebook, Twitter, eBay). Because students have first-hand daily experience with Western social networks and retailers, it should be a challenge for them to understand how Chinese consumers use the Chinese social networks and online retailing services differently.

Changes in the media landscape have coincided with rising consumer confidence and buying power among Chinese people living in all city tiers. Nevertheless, it would be a mistake to assume that these changes have led to shared consumer behaviors across tiers. Advertising strategies and appeals that resonate in one tier may not in another. Students must explore and better understand how consumer behavior varies across and is similar in different city tiers.

As Chinese buying power has risen, the relationship between consumers and brands has become increasingly important. In general, Chinese consumer behavior is characterized by a strong tendency to buy branded products. However, Chinese consumers are not terribly brand loyal (Lane et al., 2006). Although interested in buying branded gear, this is often tempered by price considerations. Compared with more developed markets, brands in China cannot charge high price premiums without running the risk of consumers switching brands. Brand loyalty only goes so far in China.

Other purchasing influences play a stronger role in China than in many Western countries. Hugely important is the influence of point of purchase marketing and the influence of salespeople (Atsmon et al., 2012). Compared to more developed markets, brand loyalty among Chinese consumers can suffer a significant falloff as they move from the consideration to the purchase stage. Last-minute brand switching can be driven by price promotions, in-store demonstrations and salespeople. Students may want to focus part of their efforts on ensuring that retailers understand well the features of OMI bicycles and that salespeople are properly trained on how to educate potential buyers about the bicycles and how to display them in stores. Often it is up to the manufacturer to work directly with retailers regarding display, as many Chinese distributors have neither the experience nor influence with retailers to do this.

Two particular advertising appeals deserve special mention. For many Chinese consumers, name-brands are an indication of quality. As the range of functional differences among brands shrinks, like it has in more developed markets, emotional appeals and imagery are more likely to be effective (Lane et al., 2006). Similarly, if market development varies across city tiers, the effectiveness of advertising appeals is likely to vary as well. Another unique element of branding in China is nationalism (Lane et al., 2006). Domestic brands often cater to national pride by emphasizing their emergence on the global stage. In general, compared with Western markets, Chinese consumers are more likely to trust domestic brands than foreign brands, although this varies by age demographic.

Thus, as they define their target markets in different cities or tiers, students should consider how to balance a message focus on the functional and quality attributes of OMI bicycles to appeal to the price-sensitive with a focus on more intangible brand building for brand-conscious consumers.

Lastly, the purchase of an OMI bike is just the first step in building a relationship with new customers. An important part of the students' planning should address how OMI can solidify and extend these burgeoning relationships post-purchase. 


\section{CASE IMPLEMENTATION EXPERIENCE}

The authors' have implemented this case multiple times as part of a study abroad trip that takes Miami University students to China, South Korea, and Japan. In each instance, Miami University students were paired with Doshisha University students and asked to craft solutions to sections of the case. Prior to meeting face-to-face with one another, Miami and Doshisha students were asked to connect via email. While the case collaboration exposes Miami and Japanese students to a variety of international management activities, the international collaboration allows for much deeper learning outcomes. Through their interactions, the American and Japanese students experience many differences and similarities between their cultures and gain valuable experience that helps them develop as future global citizens. In this section, some of the lessons learned about the intricacies of cross-cultural communication from previous implementations of the case are highlighted.

\section{English is Not a Panacea for Global Communication}

Many people seem to believe that since English is playing an increasing role as a global language, it would be possible to communicate with people around the world, as long as they can speak English. However, it would be a mistake to assume that simply because one can speak English, he or she will be able to communicate easily across borders. Even if they master English, people from different cultural spheres will not be free from possible misunderstandings unless they can grasp the true meaning of a word in a given culture. Similarly, native speakers of English will often find it difficult to communicate with local people unless they understand the indigenous culture and customs peculiar to the region. Often the scope of meaning of a given word is so varied that the meanings of the same word in two cultures scarcely overlap, even though the translation seems to be the same.

Rochelle Kopp (2002), a well-known cultural counselor in America, commented on the differences in communication style between the U.S. and Japan; "In some cases, Americans start to wonder if their Japanese colleagues are being secretive. Due to their struggles using the English language, Japanese often get exhausted trying to express themselves and give up before they have communicated all the necessary information. Another key factor creating the impression of secrecy is the 'hear one, understand ten' (tacit) communication style that Japanese have. To non-Japanese who are used to having everything on a silver platter, this communication style can easily be misinterpreted as withholding information." (p. 11) The Japanese are homogeneous people and don't have to speak and write as much as Americans do. What they say by one word, they understand ten.

\section{Examples of Findings by Japanese Students}

Prior implementations of the case have highlighted the challenges of cross-cultural communication. The following reflections by Japanese students on their collaboration with American students illustrate their perceptions of the differences in the ways that the two groups communicate:

We Japanese wait for someone to talk first, and after we hear the other's opinion, we communicate ours, even though sometimes we may change our opinion. On the other hand, Americans insist on their opinions first, before they listen to the other's opinion.

The American style of communication is straightforward. On the other hand, the Japanese style of communication is poor at expressing one's feelings to others.

During the discussion, each Miami student had his/her own idea about the problem. Then one of them asked us what we Japanese think. We were barely able to express our ideas and I cannot forget the face of surprise of the Miami students when we all had the same idea. Americans have their own ideas and stick to them. If somebody has a different idea, they will discuss it until they agree. On the other hand, Japanese tend to avoid standing out, because if you have a different idea than others, they will ask you why you think so. Japanese are very shy and passive while Americans are friendly and aggressive.

From these statements by Japanese students, one can get a clear picture that the American students really embody the American parents' teaching of 'Say what you mean and mean what you say.' Nisbett (2003) wrote in his 
The Geography of Thought that "Westerners teach their children to communicate their ideas clearly and to adopt a 'transmitter' orientation; that is, the speaker is responsible for uttering sentences that can be clearly understood by the hearer - and understood, in fact, more or less independently of the context. Asians, in contrast, teach their children a 'receiver' orientation,' meaning that it is the hearer's responsibility to understand what is being said."

\section{Ways to Achieve Smoother Communication}

The following are some suggestions to make global communication better and to avoid misunderstandings between people having different cultural backgrounds:

Try to Put One's Self in the Other's Position

Try to be empathetic toward others and give additional information, as much as possible, to increase the shared knowledge of the matter in question or the issue at stake. It is important to try and make one known to counterparts for smoother communication.

\section{Remove Colored Glasses in Order to See the World}

The understanding of what is "fact" is highly influenced by images formed within and through perceptions acquired through education and experience within cultural spheres. Before seeing empirical facts as they are, people are apt to form an image of what is seen through filtered lenses. When communicating with other people, those colored sunglasses should be removed to see the world from the perspective of others who may see the world in a completely different way, with lenses of another color.

\section{Establish Close Human Relations with Partners}

There is a saying that "successful business communication is ten percent business and ninety percent human relations." These words should be kept in mind as an important maxim for all internationally-minded persons. It is important for them to form friendly interpersonal relationships because, as general semanticists claim, "meanings reside in people, not in words." As one develops a close friendship with another person, one develops a better understanding of his or her words and phrases, and a shared perception can be achieved.

\section{AUTHOR INFORMATION}

Sooun Lee is a professor of Information Systems and Analytics and director of Higgin Kim Asia Business Program, Farmer School of Business at Miami University where he teaches courses in information systems and international business. He has developed and led several study abroad workshops in Asia. His research includes globalization initiatives and entry strategies in emerging Asian markets, software piracy, and IS education. His work has been published in numerous journals, including Information and Management, Journal of Global Information Management, Communication of the Association for Information Systems, etc. E-mail: lees@miamioh.edu (Corresponding author)

Joshua L. Schwarz is Professor of Management, Farmer School of Business at Miami University where he teaches courses in human capital metrics and human resource management. He has been involved in taking students on numerous study abroad experiences in both Europe and Asia. His research involves studies of cultural competence, especially in health care, and the impact of human resource policies on firm performance. E-mail: schwarJL@miamioh.edu

James Coyle is an associate professor in the Marketing Department of the Farmer School of Business and in Armstrong Interactive Media Studies at Miami University. His areas of research include consumer processing of information in digital interfaces, cross-cultural online communications and consumer social media sharing. His work has been published in numerous journals, including the Journal of Advertising, Journal of Advertising Research, Journal of Business Research and the Journal of Computer Mediated-Communications. E-mail: james.coyle@miamioh.edu 
Thomas Boulton is the Lindmor Professor and Associate Professor of Finance in the Farmer School of Business at Miami University. Dr. Boulton's research interests include initial public offerings, international finance, corporate governance, and mergers and acquisitions. He currently teaches undergraduate courses in investments and mergers and acquisitions and graduate courses in investments and corporate finance. E-mail: boultotj@miamioh.edu

Naoki Kameda is a professor in the Faculty of Commerce and the Graduate School of Commerce at Doshisha University, Kyoto, Japan, where he has taught international business communication and international business transactions. He completed the Graduate School of Nihon University, the doctor's course in Commerce. He was CEO of an audio manufacturer before assuming his present position in 1993. He is the author of The Study of International Business Communication, Introduction to International Business Transactions, Managing Global Business Communication, and more than a dozen other books. E-mail: nkameda@mail.doshisha.ac.jp

\section{REFERENCES}

1. Atsmon, Y., Kuentz, J., \& Seong, J. (2012). Building brands in emerging markets. McKinsey Quarterly, 4, 50-57.

2. Kopp, R. (2002, April 22). Communication problems bedevil non-Japanese execs. The Nikkei Weekly, p. 11.

3. Lane, K. P., St-Maurice, I., \& Süssmuth Dyckerhoff, C. (2006). Building brands in China. McKinsey Quarterly, 2(I), 34.

4. $\quad$ Nisbett, R. E. (2003). The geography of thought: How Asians and Westerners think differently...and why (pp.60-61). New York, NY: Free Press.

5. Noe, R. E., Hollenbeck, J. R., Gerhart, B., \& Wright, P. M. (2010). Human resource management: Gaining a competitive advantage ( $7^{\text {th }}$ ed.). (pp. 230-26). Boston, JA: McGraw-Hill Irwin. 


\section{APPENDIX}

Exhibit 1: Recent Financial Statements

\begin{tabular}{|c|c|c|c|}
\hline \multicolumn{4}{|c|}{ Income Statement } \\
\hline Period Ending & Last Year & Two Years Ago & Three Years Ago \\
\hline Total Revenue & 196,796 & 195,652 & 187,208 \\
\hline Cost of Revenue & 151,491 & 151,913 & 143,491 \\
\hline Gross Profit & 45,305 & 43,739 & 43,716 \\
\hline \multicolumn{4}{|l|}{ Operating Expenses } \\
\hline Research and Development & 1,014 & 883 & 713 \\
\hline Selling, General, and Administrative & 25,418 & 22,240 & 23,485 \\
\hline Others & 4,516 & 5,109 & 4,021 \\
\hline Total Operating Expenses & 30,948 & 28,232 & 28,219 \\
\hline Operating Income or Loss & 14,357 & $\mathbf{1 5 , 5 0 7}$ & 15,497 \\
\hline \multicolumn{4}{|l|}{ Income from Continuing Operations } \\
\hline Total Other Income/Expenses Net & $(240)$ & - & 47 \\
\hline Earnings Before Interest and Taxes & 14,117 & 15,507 & 15,544 \\
\hline Interest Expense & 3,322 & 3,628 & 3,612 \\
\hline Income Before Tax & 10,795 & 11,879 & 11,932 \\
\hline Income Tax Expense & 1,268 & 1,732 & 785 \\
\hline Net Income From Continuing Operations & 9,527 & 10,147 & 11,147 \\
\hline \multicolumn{4}{|l|}{ Non-Recurring Events } \\
\hline Effect Of Accounting Changes & $(22)$ & - & - \\
\hline Net Income & $\mathbf{9 , 5 0 5}$ & $\mathbf{1 0 , 1 4 7}$ & $\mathbf{1 1 , 1 4 7}$ \\
\hline
\end{tabular}

Note: All values are in thousands ('000). 
Balance Sheet

\begin{tabular}{|c|c|c|c|}
\hline Period Ending & Last Year & Two Years Ago & Three Years Ago \\
\hline \multicolumn{4}{|l|}{ Assets } \\
\hline \multicolumn{4}{|l|}{ Current Assets } \\
\hline Cash and Cash Equivalents & 12,881 & 11,372 & 11,254 \\
\hline Net Receivables & 26,893 & 26,456 & 25,582 \\
\hline Inventory & 36,282 & 31,029 & 32,555 \\
\hline Other Current Assets & 1,072 & 1,548 & 1,417 \\
\hline Total Current Assets & 77,129 & $\mathbf{7 0 , 4 0 5}$ & $\mathbf{7 0 , 8 0 8}$ \\
\hline Property Plant and Equipment & 15,795 & 16,439 & 18,190 \\
\hline Goodwill & 55,706 & 53,502 & 57,127 \\
\hline Intangible Assets & 29,107 & 28,138 & 29,219 \\
\hline Others Assets & 3,086 & 2,923 & 2,771 \\
\hline Total Assets & $\mathbf{1 8 0 , 8 2 3}$ & 171,408 & $\mathbf{1 7 8 , 1 1 5}$ \\
\hline \multicolumn{4}{|l|}{ Liabilities } \\
\hline \multicolumn{4}{|l|}{ Current Liabilities } \\
\hline Accounts Payable & 37,585 & 36,595 & 41,256 \\
\hline Short/Current Long Term Debt & 1,285 & 1,428 & 1,067 \\
\hline Total Current Liabilities & 38,870 & $\mathbf{3 8 , 0 2 3}$ & 42,322 \\
\hline Long Term Debt & 41,682 & 48,922 & 56,202 \\
\hline Other Liabilities & 11,436 & 9,747 & 11,164 \\
\hline Total Liabilities & 91,987 & 96,692 & 109,688 \\
\hline \multicolumn{4}{|l|}{ Stockholders' Equity } \\
\hline Common Stock & 18,062 & 18,056 & 17,455 \\
\hline Retained Earnings & 63,002 & 53,128 & 42,206 \\
\hline Capital Surplus & 673 & 404 & 120 \\
\hline Other Stockholder Equity & 7,098 & 3,127 & 8,645 \\
\hline Total Stockholder Equity & 88,836 & 74,716 & 68,427 \\
\hline
\end{tabular}

Note: All values are in thousands ('000). 
Exhibit 2: Pro Forma Income Statement

\begin{tabular}{|l|c|c|c|}
\hline \multicolumn{1}{|c|}{ Period Ending } & Year 1 & Year 2 & Year 3 \\
\hline Total Revenue & $\mathbf{8 , 0 0 0}$ & $\mathbf{1 4 , 0 0 0}$ & $\mathbf{2 0 , 0 0 0}$ \\
\hline Cost of Revenue & 4,000 & 6,000 & 8,000 \\
\hline Gross Profit & $\mathbf{4 , 0 0 0}$ & $\mathbf{8 , 0 0 0}$ & $\mathbf{1 2 , 0 0 0}$ \\
\hline & & & 2,000 \\
\hline Depreciation & 2,000 & 2,000 & 3,000 \\
\hline Selling, General, and Administrative & 2,000 & 2,600 & $\mathbf{7 , 0 0 0}$ \\
\hline Earnings Before Interest and Taxes & $\mathbf{0}$ & $\mathbf{3 , 4 0 0}$ & \\
\hline & & & 1,750 \\
\hline Income Tax Expense (25\% rate) & 0 & 850 & $\mathbf{5 , 2 5 0}$ \\
\hline Net Income & $\mathbf{0}$ & $\mathbf{2 , 5 5 0}$ & \\
\hline
\end{tabular}

Note: All values are in thousands ('000).

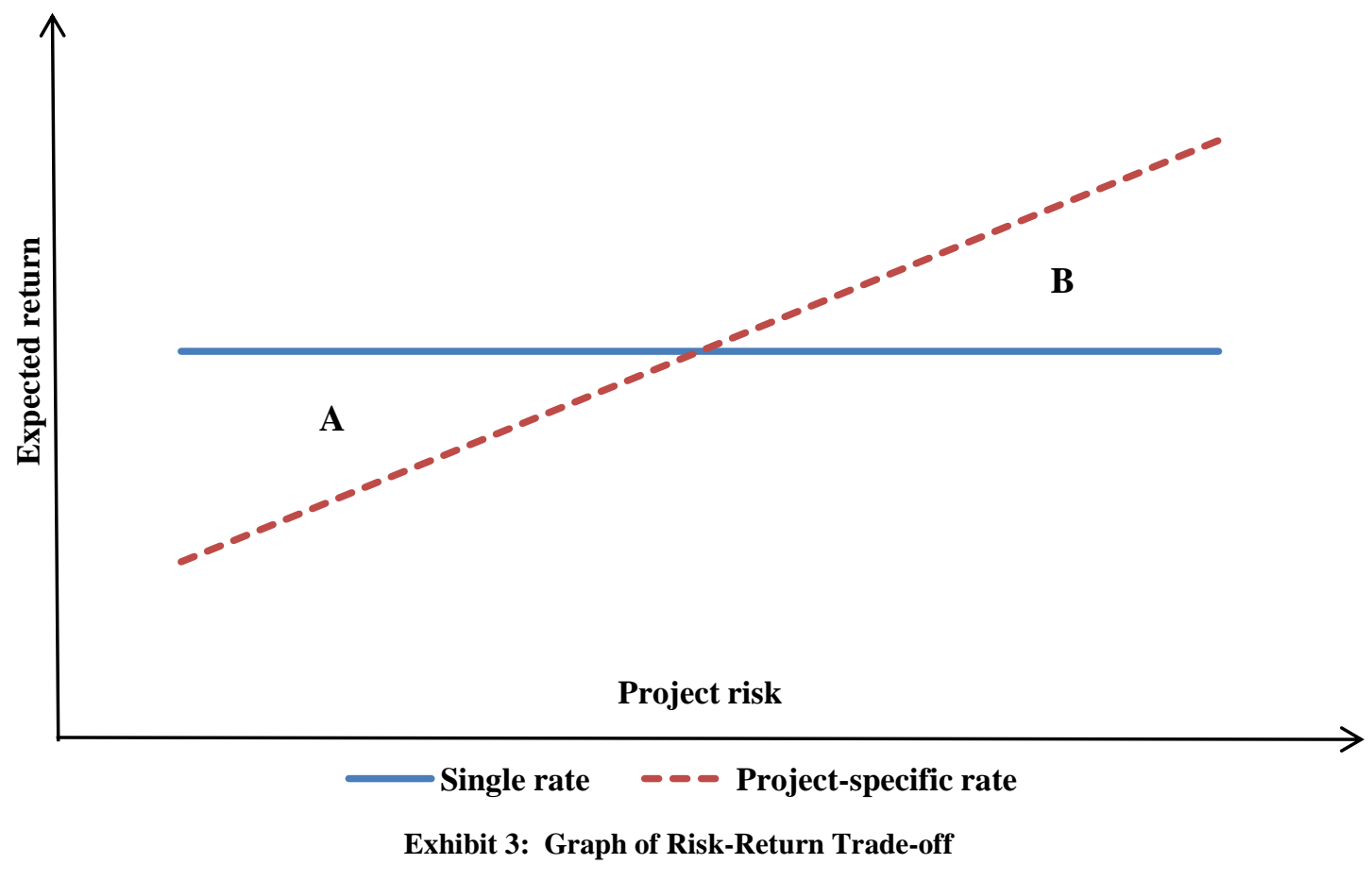


Exhibit 4: Capital Budgeting Analysis

\begin{tabular}{|c|c|c|c|c|}
\hline \multicolumn{5}{|c|}{ Joint Venture/Wholly-Owned Subsidiary } \\
\hline & 0 & Year 1 & Year 2 & Year 3 \\
\hline Initial investment & $(25,000)$ & & & \\
\hline Net working capital & $(5,000)$ & & & \\
\hline Operating cash flow & & 2,000 & 4,550 & 7,250 \\
\hline Terminal value & & & & 62,229 \\
\hline Cash flow & $(30,000)$ & 2,000 & 4,550 & 69,479 \\
\hline NPV@15\% & 20,863 & & & \\
\hline IRR & $38.45 \%$ & & & \\
\hline \multicolumn{5}{|l|}{ Representative Office } \\
\hline & $\mathbf{0}$ & Year 1 & Year 2 & Year 3 \\
\hline Initial investment & $(20,000)$ & & & \\
\hline Net working capital & $(5,000)$ & & & \\
\hline Operating cash flow & & 2,000 & 4,550 & 7,250 \\
\hline Terminal value & & & & 62,229 \\
\hline Cash flow & $(25,000)$ & 2,000 & 4,550 & 69,479 \\
\hline NPV@ @15\% & 25,863 & & & \\
\hline IRR & $47.71 \%$ & & & \\
\hline
\end{tabular}

Exhibit 5: Advantages and Disadvantages of Debt and Equity

\begin{tabular}{|l|l|l|l|}
\hline & \multicolumn{1}{|c|}{ Advantages } & \multicolumn{1}{c|}{ Disadvantages } \\
\hline \multirow{3}{*}{ Equity } & $\begin{array}{l}\text { Less risky than debt because it does not } \\
\text { require repayment. }\end{array}$ & $\begin{array}{l}\text { Higher cost of capital than debt. } \\
\text { Does not require interest payments, allowing } \\
\text { cash flows to be reinvested in the business. }\end{array}$ & $\begin{array}{l}\text { Loss of control as the investor receives an ownership } \\
\text { stake in the company. } \\
\text { You may sell stock to investors who do not share your } \\
\text { vision. }\end{array}$ \\
\hline \multirow{2}{*}{ Debt } & $\begin{array}{l}\text { The lender does not receive an ownership } \\
\text { stake and has no say in the firm's business } \\
\text { decisions. }\end{array}$ & $\begin{array}{l}\text { Debt must be repaid according to the lending agreement. } \\
\text { Interest payments consume cash that might otherwise be } \\
\text { The relationship ends once the loan is repaid. }\end{array}$ & $\begin{array}{l}\text { Debt introduces the possibility of bankruptcy and its } \\
\text { associated costs. }\end{array}$ \\
\hline
\end{tabular}


Exhibit 6: Project Manager Position Description

Project Manager reports to the CEO and executive committee of OMI.

Summary Position Description: Project Manager (PM) oversees all aspects of OMI's proposed entry into the Asian bicycle market including: planning, monitoring and controlling processes. PM is responsible for co-ordination and completion of the project to establish OMI in the Asian market and will perform a variety of tasks including setting deadlines, assigning responsibilities, and monitoring and summarizing progress of the project.

Detailed Position Description: PM has authority to run the project on a day-to-day basis on behalf of OMI. PM will have sufficient latitude to exercise a wide degree of creativity in performing this role.

\section{Planning and Problem-Solving Tasks}

1. $\quad \mathrm{PM}$ is responsible for planning the project to accomplish its goals or produce the business plan/proposal required within constraints of time, cost and agreed quality standards.

2. $\quad \mathrm{PM}$ is responsible for maintaining the project budget. If necessary, a specialist may help prepare the budget for the PM's review. PM will have ownership of the budget. The PM's budgetary responsibility requires that they are able to understand it enough to take responsibility for delivering the project within the budget defined.

3. PM must continuously monitor progress in terms of the status of the plan and budget and report back to the CEO and executive committee via weekly or other progress reporting and by organizing and managing status and board meetings.

4. PM must anticipate and catch deviations from a plan or schedule early and keep all stakeholders informed.

5. PM should identify, log, analyze and manage potential and actual issues/risks, taking corrective action by tackling day-to-day issues head on and reviewing how more serious issues/risks might impact scope, schedule, quality and cost.

6. PM will identify where and when management of issues/risks or accommodating altered requirements will involve extra time or resources and where efficiencies can be made.

\section{Communicating Tasks}

1. PM articulates and negotiates consensus on a final vision of the product and/or the core project goals from scoping the requirements of all stakeholders.

2. PM defines acceptance criteria for project deliverables and works towards achieving stakeholder acceptance of recommendations.

3. PM is professional in all written and oral communication, and communicates non-confrontationally in one-to-one situations, small groups, and before large audiences.

\section{Team Management Tasks}

1. PM identifies resource needs and team management responsibilities.

2. PM works directly with the team members to estimate effort, plan activities and negotiate consensus on their appointed tasks.

3. Third party contractors, managed and coordinated by the PM, who may do some parts of the work.

4. $\quad$ PM exercises good judgment in managing tasks.

5. PM should be able to create and use Gantt charts, spreadsheets or other appropriate project management tools to manage people and tasks.

6. PM may need experience in providing a team with direction and vision, including motivating people to perform, listening to people, providing feedback, recognizing strengths and providing challenges.

\section{Technical and Quality Tasks}

1. PM must understand relevant methodologies, processes and standards and ensure all project team members understand and follow these.

2. PM is responsible for the project's commitment to product quality.

\section{Organizing Tasks}

1. PM may need to generate documents, including requirement specifications, contracts, schedules, personnel records, project reports, communication (email) records, design specifications, meeting agendas, minutes and status reports.

2. PM may need to create a structure for project documentation and remain conscientious in using it and ensuring that the rest of the team understands and uses it.

\section{Knowledge, Skills and Abilities Necessary}

1. Education and experience are flexible as long as candidate has a proven record of leadership or strong potential to provide it in the context of this project. 
Exhibit 7: Selection Criteria Scores

\begin{tabular}{|l|c|c|c|c|c|c|c|}
\hline Candidate & CEO & VP Mktg. & VP Operations & VP HR & Intelligence & Physical Fitness & Graphology \\
\hline Robert & 9 & 7 & 10 & 8 & 132 & 5 & 3 \\
\hline John & 8 & 9 & 9 & 9 & 120 & 4 & 5 \\
\hline Lisa & 7 & 9 & 5 & 10 & 128 & 2 & 10 \\
\hline
\end{tabular}

Notes: For all scores, higher numbers indicate stronger performance. Interview scores 1-10, Intelligence based on IQ score where $100=\mathrm{US}$ Average, Physical Fitness 1-5, Graphology 1-10. 